\title{
PREDICTING MUD MOTOR PERFORMANCE AND RELIABILITY WITH REDUCED ORDER MODELING
}

\author{
ANTON KOLYSHKIN ${ }^{1}$ \\ ${ }^{1}$ Schlumberger Technology Corp. \\ 23400 Colonial Pkw., Katy, TX 77493, USA \\ AKolyshkin@slb.com and www.slb.com
}

Key words: FEM, Mud Motors, Elastomer Modeling

\begin{abstract}
In this paper we present a reduced order model for simulating mud motor performance and reliability. The model breaks down a mud motor power section to a set of 2D simulations with simplified drilling fluid flow description. It can reliably predict power curves and failure risks caused by elastomer fatigue, hysteresis heating, and debonding. The model can capture mud compatibility effects as well. Due to relatively short simulation time, it becomes feasible to perform simulations for new motor design, elastomer, failure analysis, or to find optimal motor type, elastomer, interference fit, and differential pressure for a specific job.
\end{abstract}

\section{INTRODUCTION}

Mud motors have been widely used in directional drilling since the 1960s. They are rather cheap and commoditized, robust and powerful, and easy to manufacture and maintain. It is believed that more than $60 \%$ of directional drilling jobs are performed with mud motors. Even after introduction of advanced rotor steerable systems (RSS) in the 2000s, the usage of mud motors did not decrease, as apparently coupling a mud motor and RSS brings synergetic effects of improved control and drilling speed, so now some motors are specifically designed for such application.

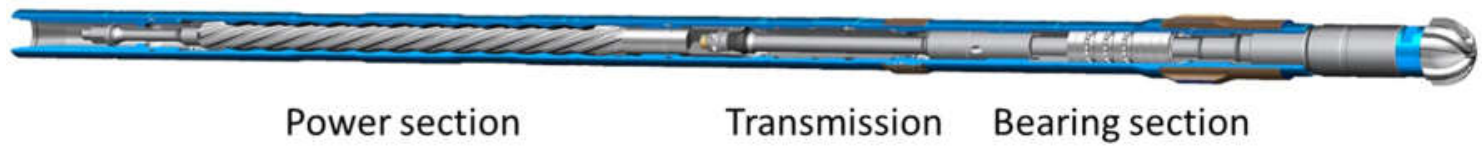

Figure 1. Mud motor layout

A mud motor consists of three main parts: power section, transmission, and bearing section (Figure 1). The power section is responsible for torque generation, i.e. it converts hydraulic energy of drilling fluid to mechanical energy of planetary rotor rotation. The transmission transforms planetary rotation to simple rotation and possibly passes it through some angle formed by the motor corpus. The bearing section takes the axial load from rotor and transmission. The mud motor drives the drilling bit either directly or through RSS.

Power section assemblies are the most critical part of the mud motors [1]. Mud motor 
performance and reliability mostly depend on power section design and materials. The power section is the most sensitive to operating conditions and generally defines the motor operating conditions. Most mud motor failures are, in fact, power section related.

The power section itself consists of two parts: rotor and stator (Figure 2). The mud motor rotor is usually made of stainless steel and coated either with hard chrome or tungsten carbide to give extra protection from corrosion and abrasion. The mud motor stator is typically a metal tube (optionally profiled), which has rubber limning inside. Both rotor surface and stator interior have special helical surfaces, so, when assembled, they form a set of closed cavities. The rotor can perform planetary motion inside stator. During such rotation, the cavities move along the power section while remaining sealed.

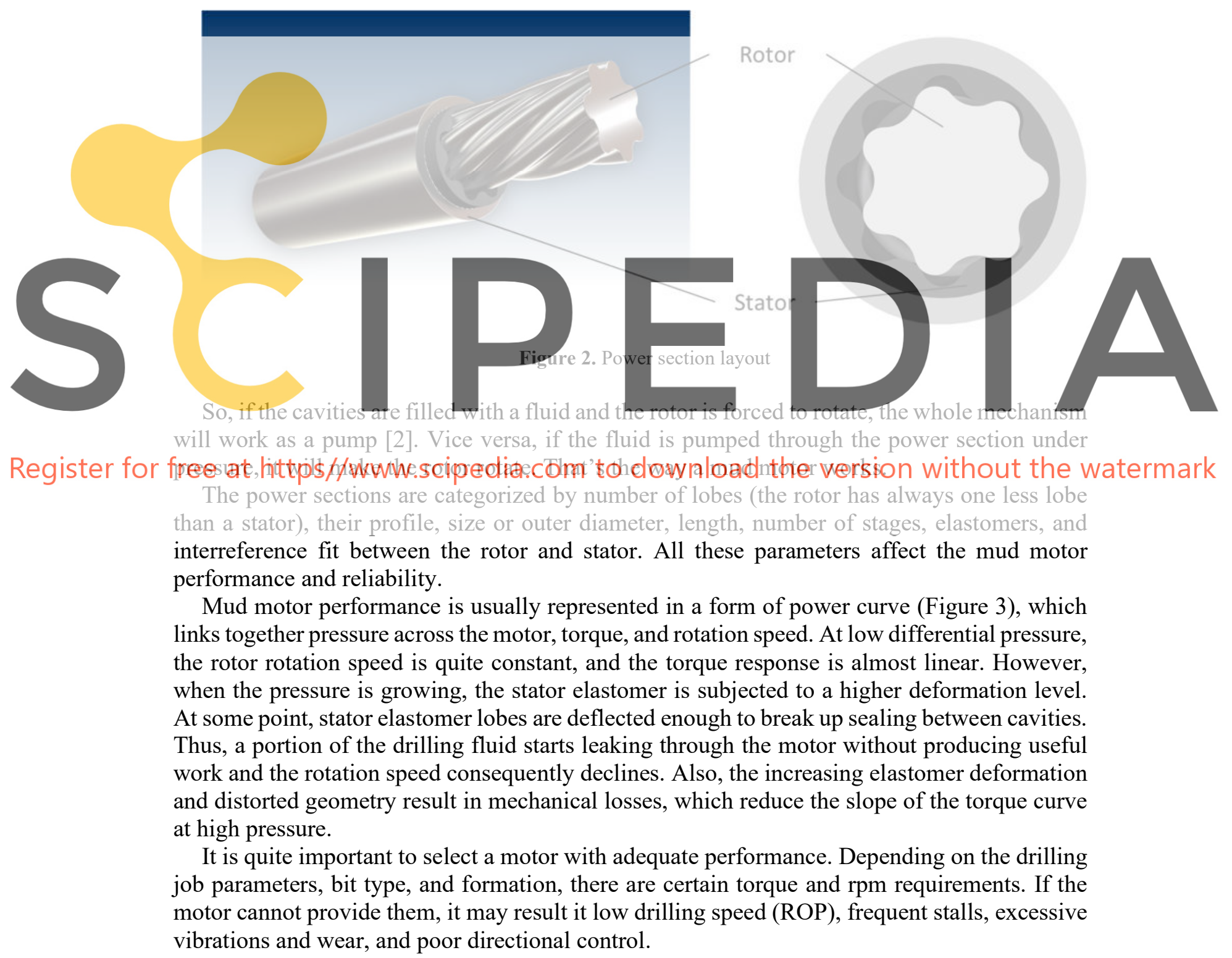




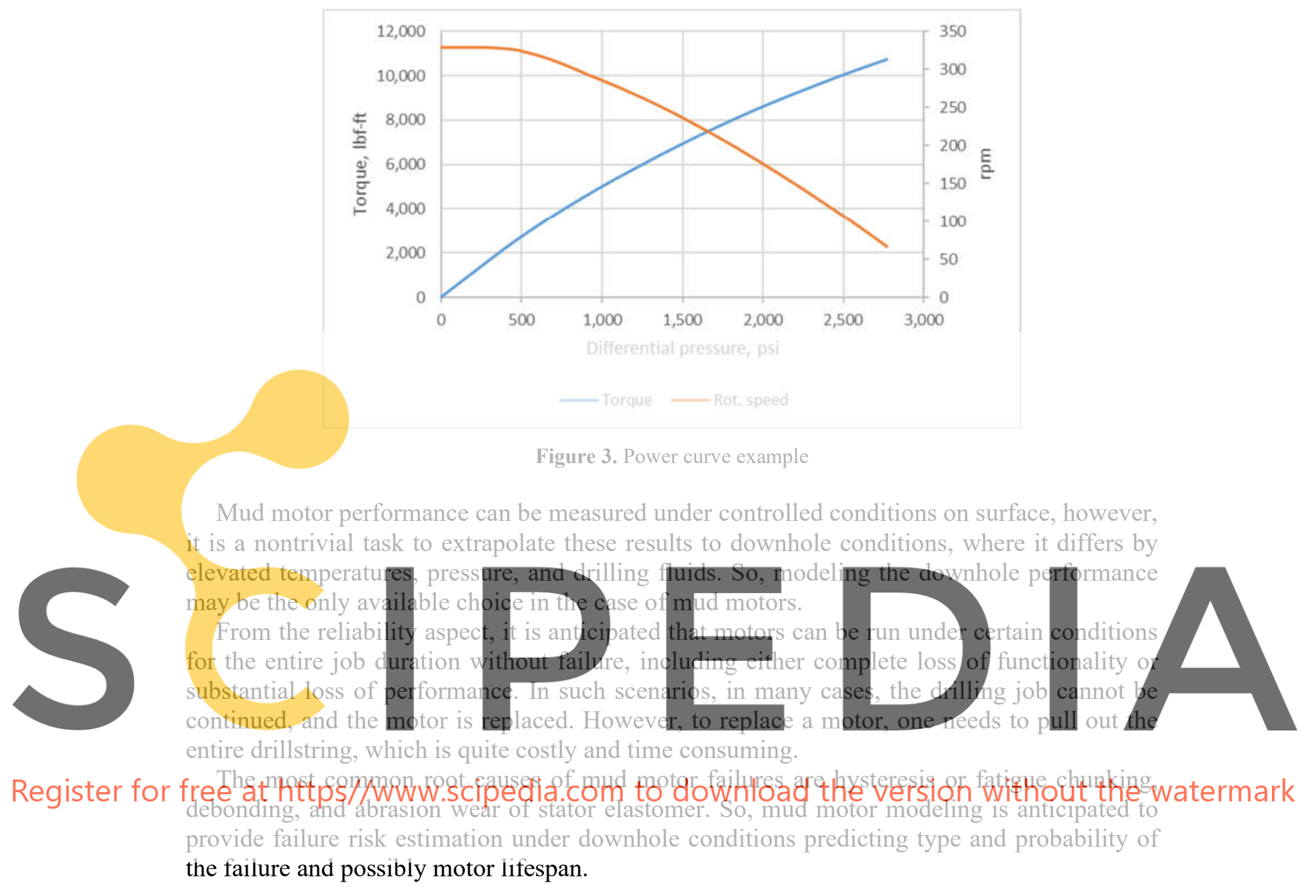

\section{MODELING CHALLENGES AND OBJECTIVES}

Despite being quite simple in design, the power section of a mud motor is very challenging for modeling. The first problem is quite complex kinematics. The rotor performs planetary rotation inside the stator, which is identical to a circle rolling inside a bigger circle (Figure 4) Thus, the rotor not only rotates in the external reference frame, but its center rotates around the stator center as well. The contact between rotor and stator lobes changes from pure sliding to pure rolling.

Then, the stator elastomer brings to the model nonlinear friction, large deformations, and viscoelasticity. This requires more characterization, increases model complexity, and boosts the computation cost.

Finally, interaction with the drilling fluid must be taken into account as well. The drilling fluid hydrodynamics is a key for mud motor performance modeling. In addition, the drilling fluid can interact chemically with the elastomer, changing its properties. 


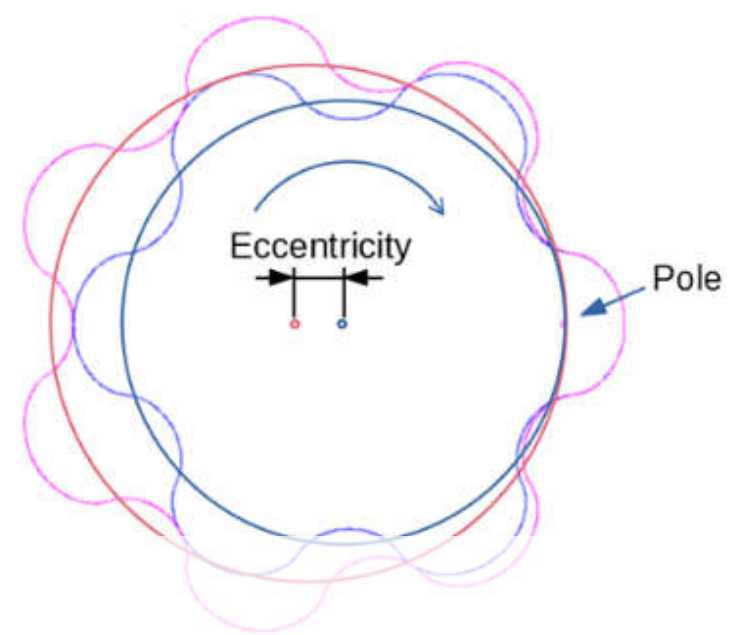

Figure 4. Rotor motion is similar to a circle roiling in another circle

There have been several published works dedicated to mud motor modeling, however, many of them had to sacrifice one or more aspects mentioned above. In some publications the authors used fully theoretical approach [3], empirical [4] or based on big data [5]. There are several papers showing results of nodeling a particular aspect of mud motor operations, like fluid dynamics [6], hysteresis [7] or kinematics [8]. Some time ago, derive motor perfor elastomer deformation took a significant am developr ance and reliability [9]. , press distribution, some important effects as well, for example, hysteresis heating.

hundreds of models, and there is always a choice of a different elastomer or interference fit, we need to have a modeling tool which can predict motor performance and reliability in a reasonable amount of time. So, while working on the full-scale 3D model, we have been developing a reduced order model with simplified geometry and some physical processes. The primary focus was reduction of computation costs to make the model an effective engineering tool.

\section{THE MODEL DESCRIPTION}

In order to have a fast and scalable algorithm, two major simplifications have been made in the model:

a set of 2D simulations is conjugated to represent dynamic behavior of stator elastomer; drilling fluid dynamics are reduced to a cavity network, which is connected through gaps, and there is no mechanical interaction between the fluid and elastomer.

The first assumption is based on the periodicity of power section geometry and the fact that due to the rotor motion inside stator, each stator cross section is dynamically equal to another. If rotor and stator are undeformed and the eccentricity is constant over the entire length of the power section, each subpitch becomes identical to any other (Figure 5a). So, assuming small 
rotor and stator deformation, when modeling a power section, we can reduce the full power section geometry to just one pitch length.

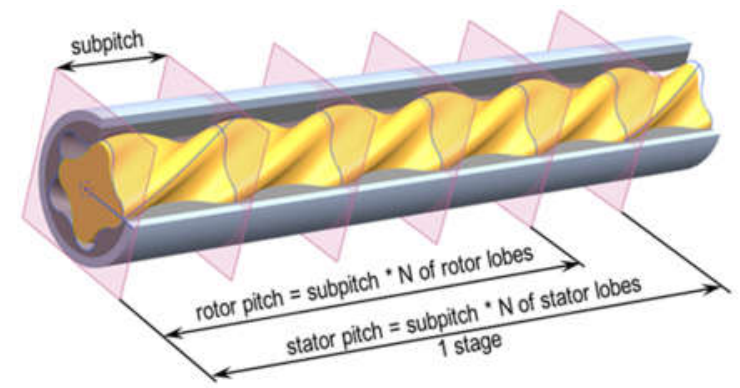

$a$
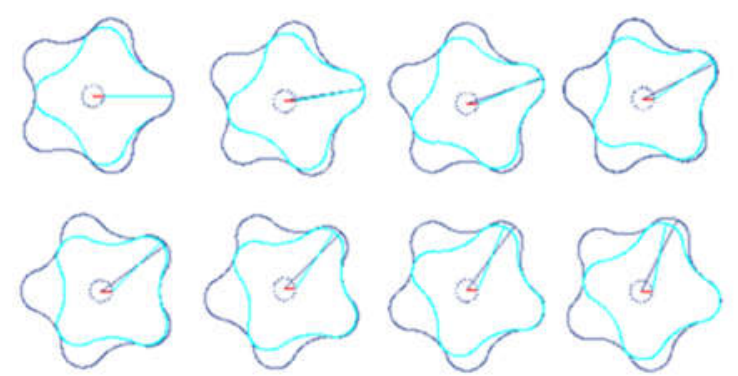

$b$

Figure 5: Power section geometry periodicity (a) and relative rotor position in different cross sections (b)

In addition, within subpitch, each 2D cross section is identical as well. While the moving rotor is taking all possible positions inside the stator (Figure 5b), all cross sections undergo the same deformation cycle, but shifted in time. The shift in time is proportional to the distance between them and the rotation frequency.

Furthermore, the stators and rotors of mud motor power sections are normally designed to

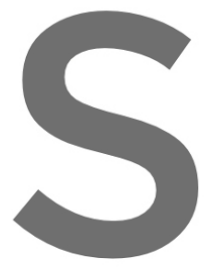

have identical lobes cycle as any other as the deformation cyd

Thus, the modd treats deformation, and the forces f that the deformation in the direction of the po rno

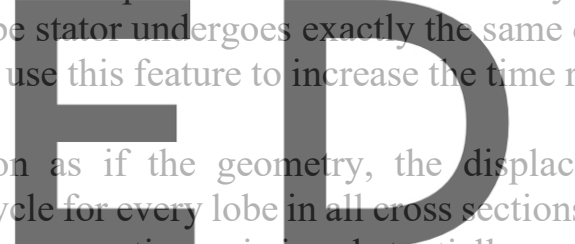
the perpendicular directions, which is confirmed by 3D modeling, we can perform 2D modeling

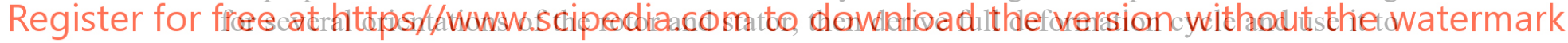
reconstruct 3D geometry. This approach is anticipated to be very relevant in the middle of the power section, however, it may result in some potentially higher deviations at both ends.

The FEA mesh is created only for stator elastomer, assuming the stator tube and rotor to be infinitely rigid. Nonlinear elasticity model is used as constitutive model of rubber [10]. This model requires only simple tension test results and bulk modulus. Since rubber elasticity significantly depends on temperature, the normal practice is to perform the tests in the temperature range from ambient to up to $200 \mathrm{degC}$, which completely covers mud motor field applications.

The FEA is performed for different relative orientation between the rotor and the stator. All the orientations are linked through the rotor orbit constrains. The solutions can be decomposed into time sequences of rotor motion and elastomer deformations. This time sequence is looped, i.e., it represents full deformation cycle and is used for hysteresis processing.

In simple words, hysteresis is a lapse between deformation and stress response in cyclic loading. The phase angle between them, or namely its tangent value $\tan \delta$ is used to characterize elastomer viscoelasticity. It normally depends on loading frequency, amplitude, and temperature, thus, a set of tests under different conditions is required for proper characterization. 


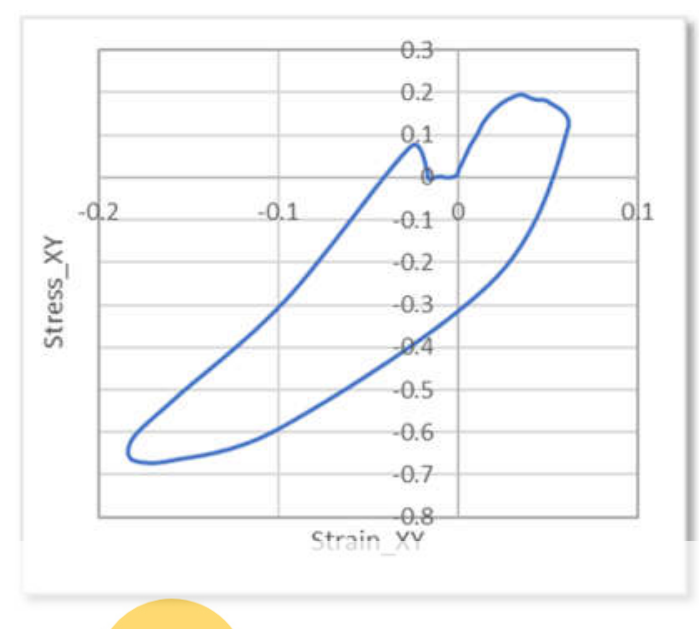

$a$

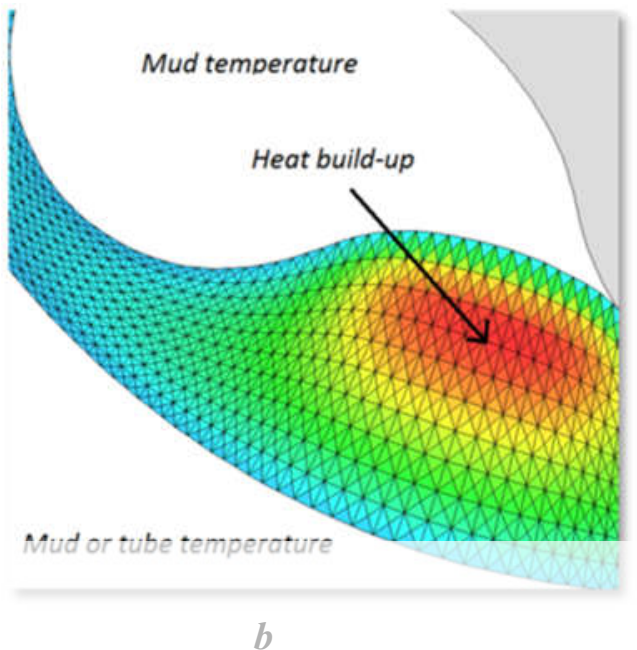

$b$

Figure 6. Hysteresis loop (a) and temperature field (b) of a power section.

In order to apply viscoelasticity, fast Fourier transform (FFT) is performed for each element of the model. It results in modified element stress, which is used as input for next iteration of the FEA. After several iterations FEA $>$ FFT $>$ FEA, the stress and strain values converge with some reasonable tolerance, and we have hysteresis loop for each element in the strain-stress coordinates. (Figurd 6a). The area within the loop effectively is the deformation energy loss due to the heat per deformation cycle. The heat buildup rate is the product of the loading frequency and heat loss per cycle. By having heat buildup rate for each element and mud temperature a boundary conditions (Figure 6b), we can solve either steady or transient themal proble get temperatures in each element. This temperature field properties and get more accurate simulation results on the next iteration, but also high internal

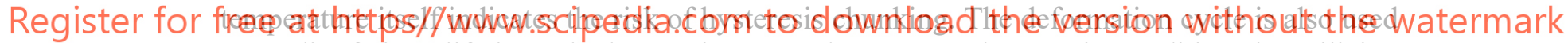
to predict fatigue life in each element in stator elastomer under certain conditions by utilizing either Lake-Lindley or Tomas model [11].

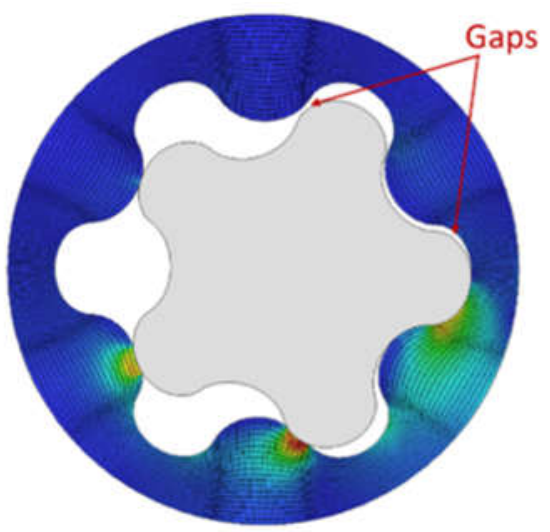

Figure 7: Gaps between rotor and stator. 
To determine the loading frequency, and hence, hysteresis heat buildup and fatigue life in hours, one needs to know the motor rpm. Theoretically the motor rpm is proportional to the flow rate, however, due to the rubber deformation, some gaps appear between adjacent cavities (Figure 7) forming path to drilling fluid leakages and, thus, loss of rpm. The rpm reduction is proportional to the fluid loss through leakages.

In order to find the amount of leakages, we determine the gap area between cavities and use the orifice plate model for incompressible fluid. The pressure in the cavities and torque are determined from the rotor force balance.

The entire algorithm is implemented as standalone executable code, which is available to power section designers and engineers and can be embedded into higher level systems [12].

\section{MODELING RESULTS}

The model takes as input real stator and rotor profiles, power section length, and pitch. The required elastomer properties include stress-strain curves, $\tan \delta$ values at different temperatures, coefficients for fatigue models, friction parameters for Thirion equation [13], optionally parameters for Mullins softening, permanent set, and abrasion. The operating conditions include flow rate, downhole temperature, and pressure. There is also an option to include mud diffusion into elastomer, which may cause volume change and affect rubber stiffness and fatigue life.

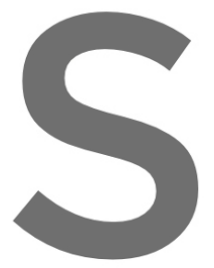

The algorithm model predictions downhole conditions control of drilling prov it enables proper mot an important factor, as low impact motor reliability.
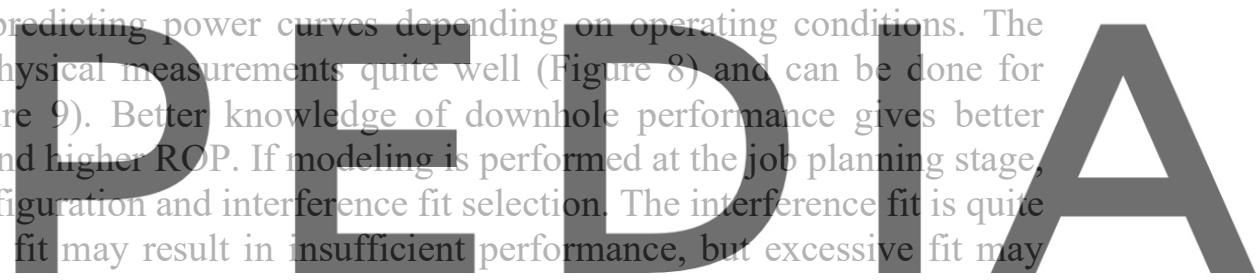

Register for free at https//www.scipedia.com to download the version without the watermark
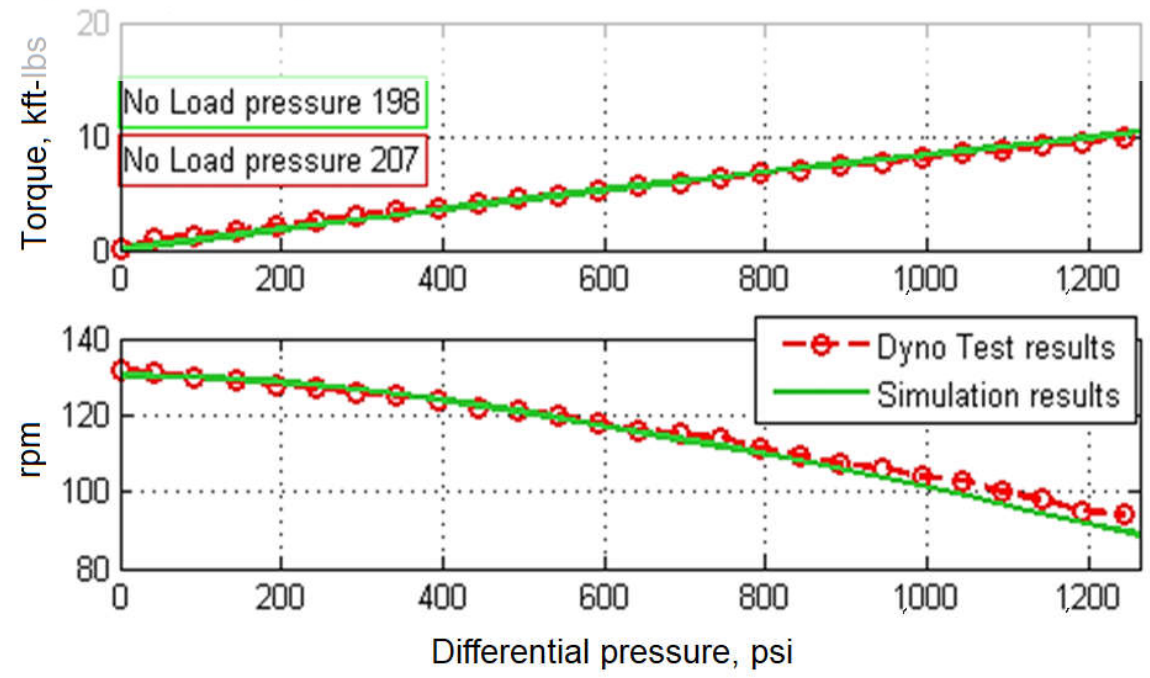

Figure 8. Power curves simulation vs. Dyno test at ambient temperature. 


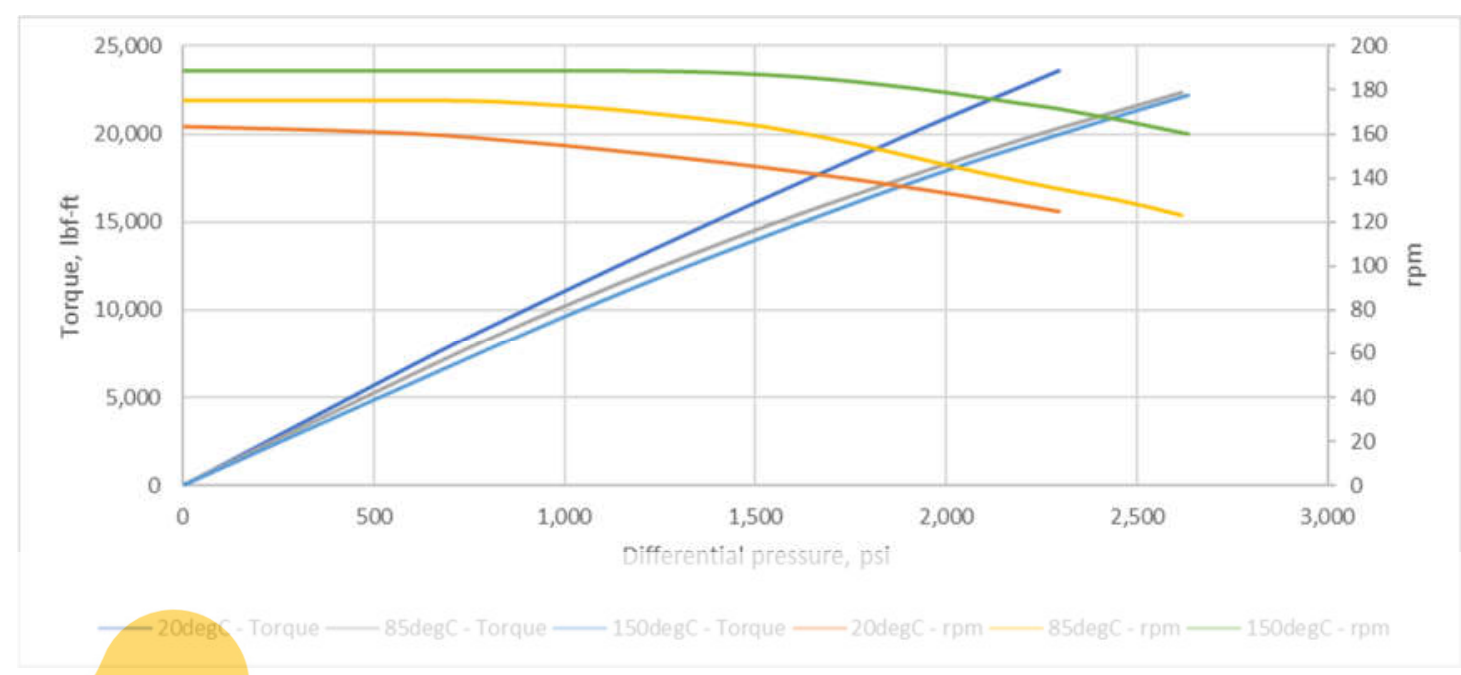

Figure 9. Power curves evolution with temperature

The mud motor reliability can be considered through three main risks: fatigue, hysteresis, and debonding. Fatigue is the process of gradual initiation of microscopic cracks and their subsequent growth to macroscopic size under cyclic load. During typical mud motor lifespan, the elastomer is subjected to some millions of deformation cycles, so fatigue failure is a rather common issue.

The debonding process is similar to the fatigue, however, in the appear and propagate at the interface between rubber and meta 1 finally result in the disin integration of elastomer lining and 1

The erack grow th rate depends on cracking energy density

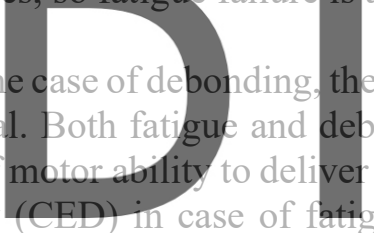
a rather debonding energy (DE) in case of debonding, both being a portion of strain energy available

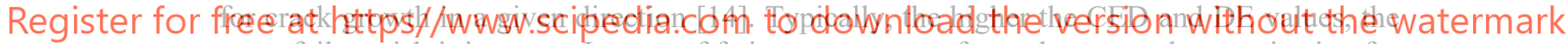
more failure risk it imposes. In case of fatigue, we can perform elastomer characterization for the fatigue models, which can predict service life of motor in hours.

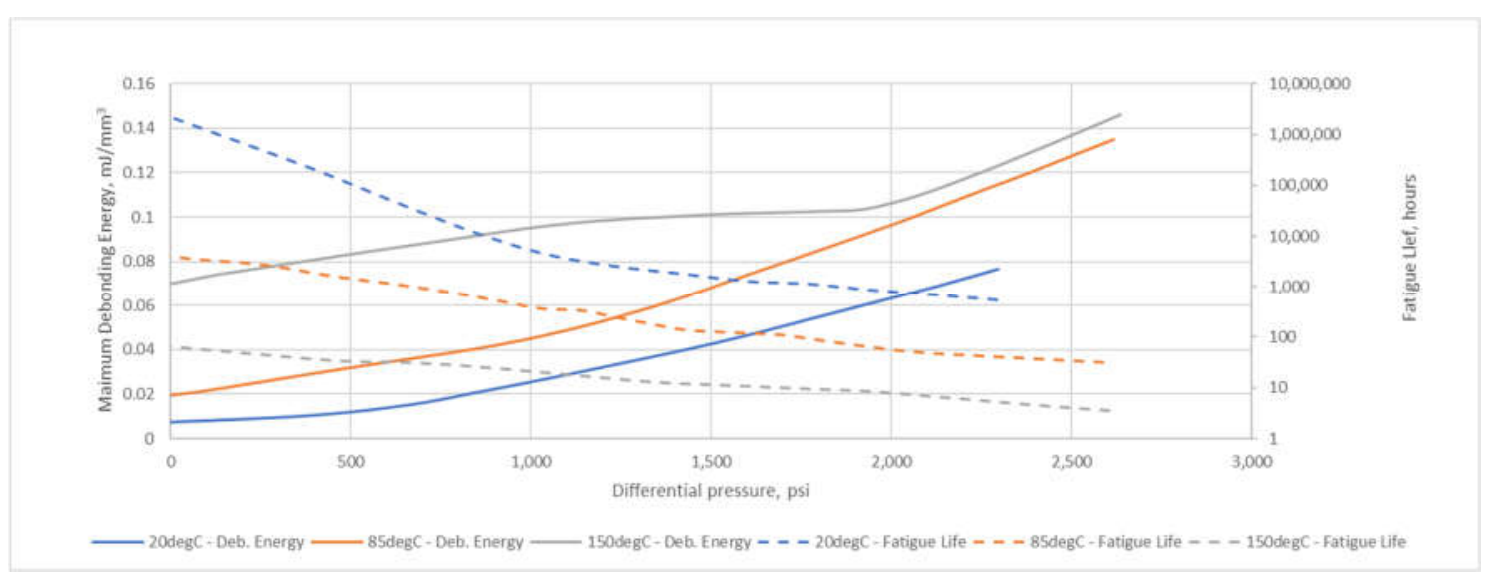

Figure 10. Fatigue life and debonding energy at different temperatures 
Figure 10 shows how the fatigue life and debonding energy depend on differential pressure and temperature for the same power section. Growing differential pressure reduces fatigue life because of higher deformation level. The temperature has two effects in increasing interference fit and weakening the elastomer. As the result, if there is negligible risk of fatigue failure at 20 $\operatorname{degC}$, at $150 \operatorname{degC}$ the predicted fatigue life is lower than $100 \mathrm{~h}$, even at small differential pressures. Although it is not possible to avoid elastomer weakening at high temperatures, adjusting the interference fit could improve the situation.

Hysteresis heating can promote fatigue or debonding or may cause failure by itself. During cyclic deformation, some part of deformation energy is lost and released as heat during each cycle. Mud motor typical loading frequencies lay in the range of $10-30 \mathrm{~Hz}$, so it can be a tremendous amount of heat. Rubber is a poor heat conductor, thus, the temperature inside the rubber lobe may significantly exceed mud temperature or even reach the value sufficient to start rapid chemical degradation. As the growing temperature causes rubber thermal expansion and hence, the growth of the interference fit, the deformation energy grows as well, and in some circumstances may form positive feedback.
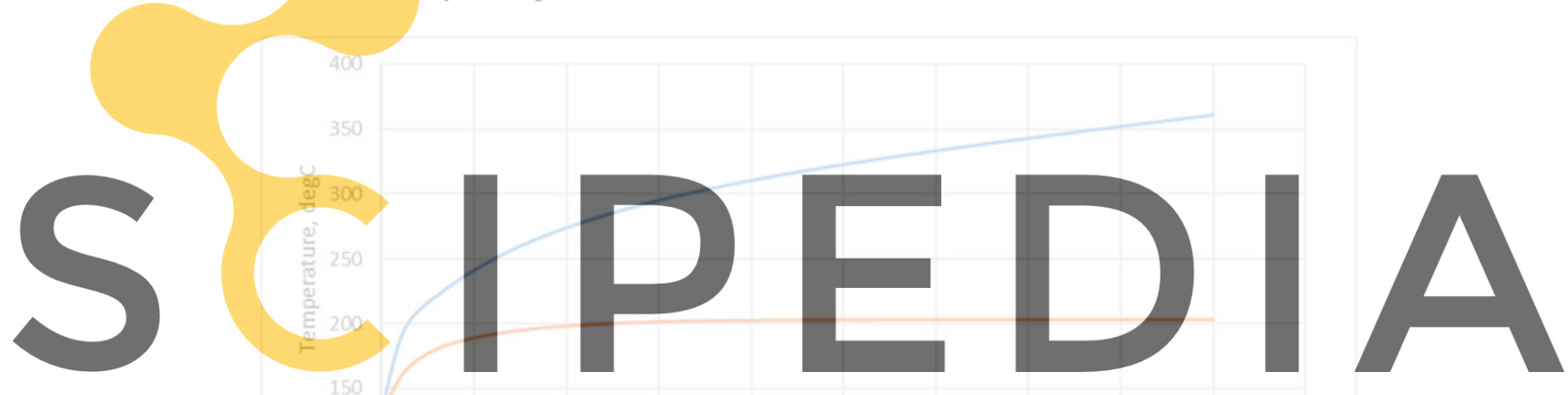

Register for free at https//www.scipedia.com to download the version without the watermark

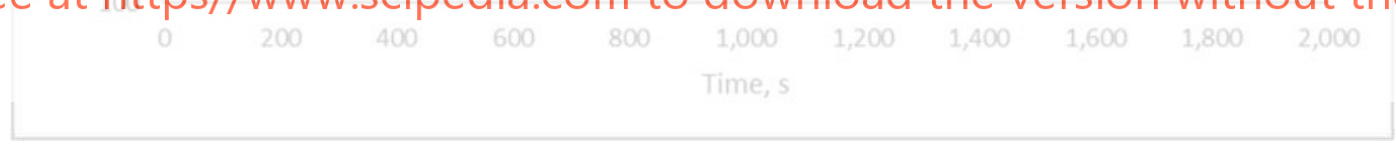

Figure 11. Maximum temperature evolution for two elastomers

Figure 11 gives an example of such feedback. It shows how the maximum elastomer temperature will evolve in two power sections run under constant load. The power sections differ only by elastomer type, which have different value of $\tan \delta$. The elastomer with the lower value approaches equilibrium after about 10 minutes. In the case of the other elastomer, the amount of generated heat is higher, and the continuing thermal expansion does not reach the equilibrium. In practice it means that the elastomer temperature reaches a dangerous level with its rapid deterioration and consequent failure.

The chemical interaction between drilling fluid and stator elastomer can also alter power section performance and reliability. The drilling fluid can diffuse in the elastomer or extract its components causing its volume and stiffness and fatigue life reduction as well. To take the effects into account, we can model mud diffusion in the elastomer (Figure 12) and modify each element property to include mud effect. 


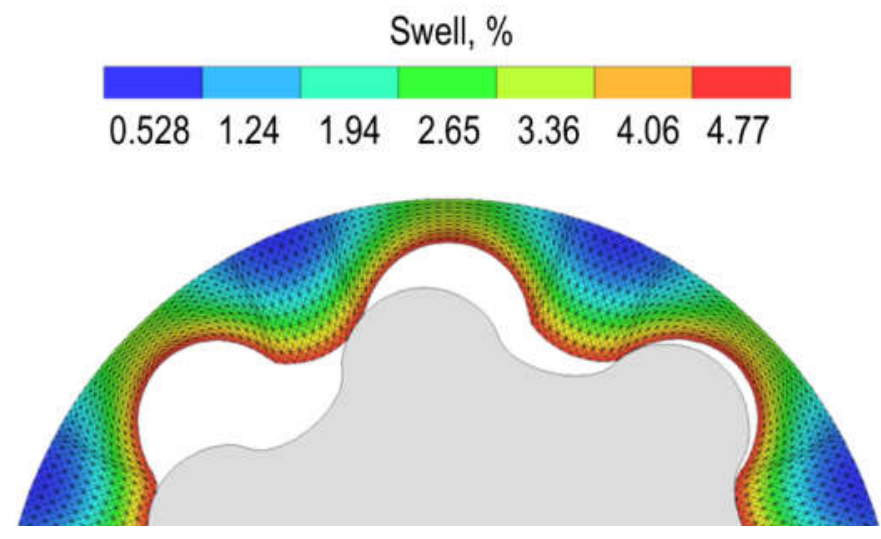

Figure 12. Stator elastomer swell distribution

This way we can simulate performance and reliability after some prolonged contact with a drilling fluid, like shown on Figure 13. As seen there, $100 \mathrm{~h}$ contact with oil-based mud caused a significant swell of elastomer in conjunction with weakening, decreasing the estimated fatigue life by few orders of magnitude. In this case, the reduction of the failure risk can be achieved by adjusting the interference fit and optionally replacing the elastomer for more resistant one to this type of the drilling fluids.
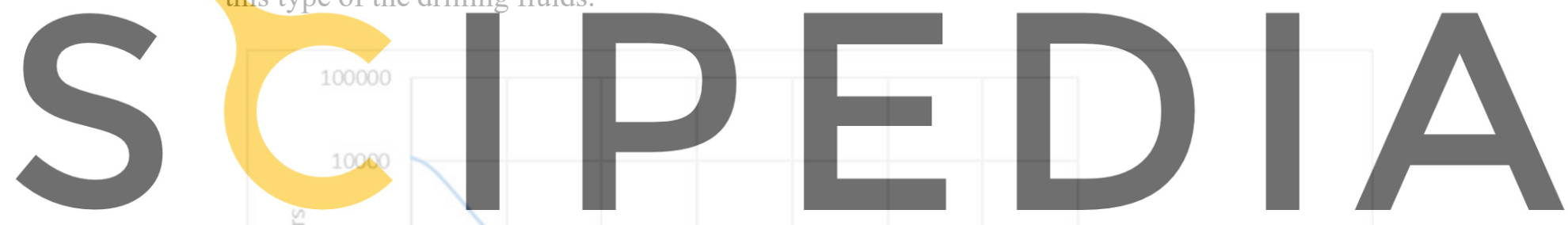

Register for free at https//www.scipedia.com to download the version without the watermark

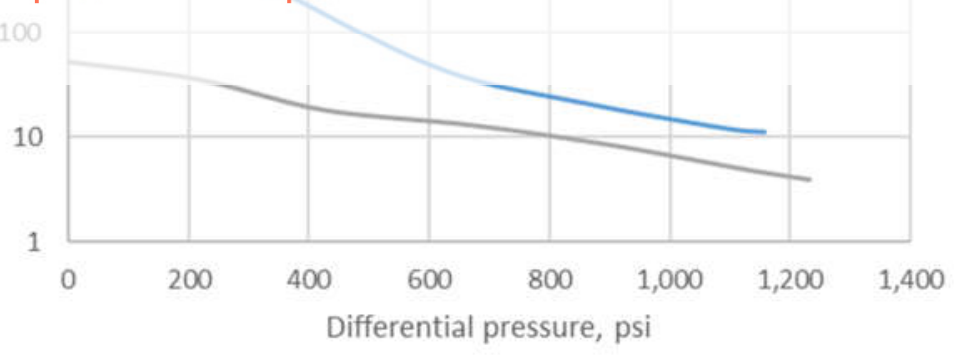

Figure 14. Mud compatibility effect on power section fatigue life.

All the simulations discussed above can be performed in a rather small amount of time. For example, simulation at one particular load condition, e.g. constant torque or pressure, takes several minutes, deriving a power curve takes less than an hour, and hysteresis simulation for constant load can be done within 20 minutes. That enables using this model for routine engineering tasks, as power section design optimization, motor selection during job planning, 
and failure analysis.

It drastically improved motor reliability and solved long-lasting problems with drilling efficiency, as shown in [15]. It was used in development of new commercially available elastomers with higher pressure rating. The model predictions are used to perform a cumulative damage analysis to assess the risk of extending the usage of a motor [16]. Finally, abundance of modeling results enabled some higher level systems designed for motor usage optimization.

\section{CONCLUSIONS}

We developed a reduced order model of mud motor power section, which enables predicting mud motor performance and reliability depending on:

Real stator and rotor geometry, elastomer properties, interference fit, downhole temperature, flow rate, mud compatibility

The results are output as physical quantities and may include:

pressure, torque, rpm, fatigue life in cycle or hours, bonding stress or debonding energy, maximum temperature due to hysteresis heating

Thus, from a technical point of view, the reduced order model enables:

- selecting an optimal power section, elastomer, and interference fit for given conditions, which provides both adequate performance and reliability;

- perform failure analysis;

- optimize power section design;

- provide recommendations for optimal operating conditions;

- derive elastomer properties to meet performance and reliability requirements.

\section{REFERENCES}

[1] Tiraposlky, W. Hydraulic Downhole Drilling Motors: Turbodrills and Positive Displacement Rotary Motors. Houston: Houston Gulf Publishing Co. (1985).

[2] Moineau, R. J. L. Gear Mechanism. Patent US-Patent 1892 217. (1931).

[3] Nguyen, Tan C., E. Al-Safran, and V. Nguyen. "Theoretical modeling of positive displacement motors performance." Journal of Petroleum Science and Engineering 166 (2018): 188-197.

[4] Yánez, E., Arredondo H., Micksu H. "Management and Best Practices of Progressive Cavity Pumps Failures Huyaparí Field, Orinoco Oil Belt." Paper presented at the SPE Artificial Lift Conference-Americas, Cartagena, Colombia, May 2013. doi: https://doi.org/10.2118/165061-MS

[5] Zhang, Zh., Shen, Y., Chen, W., Zhenyu Ch.. "Analyzing Energy and Efficiency of Drilling System with Mud Motor through Big Data." Paper presented at the SPE Annual Technical Conference and Exhibition, Virtual, October 2020. doi: https://doi.org/10.2118/201502-MS

[6] Paladino, E., Alves de Lima, J, Almeida, R., Assmann B.W. "Computational Modeling of the Three-Dimensional Flow in a Metallic Stator Progressing Cavity Pump." Paper presented at the SPE Progressing Cavity Pumps Conference, Houston, Texas, USA, April 2008. doi: https://doi.org/10.2118/114110-MS

[7] Delpassand, M. S.). "Stator Life of a Positive Displacement Downhole Drilling Motor." 
ASME. J. Energy Resour. Technol. June 1999; 121(2): 110-116.

[8] Aage, N., Donaldson, J., and Feng, Y. "Mathematical Problems for Moineau Pumps." 57th European Study Group Mathematics with Industry (ESG157). (2006). 1-48

[9] BA, S., Pushkarev, M., Kolyshkin, A., Song, L., Yin L.L.. "Positive Displacement Motor Modeling: Skyrocketing the Way We Design, Select, and Operate Mud Motors." Paper presented at the Abu Dhabi International Petroleum Exhibition \& Conference, Abu Dhabi, UAE, November 2016. doi: https://doi.org/10.2118/183298-MS

[10] Kaspar, William J. Consitutive models for engineering materials. Encyclopedia of Physical Science and Technology. Third Edition. V.3 (2002). 603-633

[11] Lindley PB. Energy for crack growth in model rubber components. Journal of Strain Analysis. 1972;7(2):132-140. doi:10.1243/03093247V072132

[12] BA, S., Belov, D., Nobre, D., Yin, L. L., Johnson, E.. "Combined Data Analytics and Physics-Based Simulation for Optimum Bit, Motor, BHA Combination." Paper presented at the Offshore Technology Conference Brasil, Rio de Janeiro, Brazil, October 2019. doi: https://doi.org/10.4043/29875-MS

[13] Thirion, P. Rev. Gen. Caoutch., 23, 101 (1946).

[14] Mars, W. V. Cracking Energy Density as a Predictor of Fatigue Life under Multiaxial Conditions. Rubber Chemistry and Technology 1 March 2002; 75 (1): 1-17. doi: https://doi.org/10.5254/1.3547670

[15] Beeh, H. A., Nobre, D., Ba, S., Yan, X. , Lauritsen, A. , Døssland, Ø. , Hodne, J. "Drilling a Challenging Kvitebjørn Field 53/4-in. Section in a Single Run Using a New Mud Motor Modeling Engineering Workflow and New Long-Life Elastomer." Paper presented at the SPE Norway One Day Seminar, Bergen, Norway, April 2018. doi: https://doi.org/10.2118/191331-MS

[16] S. Ba, A. Kolyshkin. Determining the life span of an elastomer in a motor. Patent USPatent 10139326 (2018). 